\title{
MICROSTRUCTURE AND TEXTURE EVOLUTION IN TEMPER ROLLED Fe-Si STEELS WITH NEW SYSTEM NANO-INHIBITORS UNDER THE DYNAMIC ANNEALING CONDITIONS
}

\begin{abstract}
This work investigates the microstructure and texture evolution in grain-oriented electrotechnical steel with a new inhibition system based on vanadium carbides nano-particles. The novel approach for the preparation of this steel with appropriate final magnetic properties combines not only nanoinhibitors based on the vanadium carbides precipitations but also includes straininduced grain growth mechanism in combination with dynamic continuous annealing during the secondary recrystallization. The experimental grain-oriented steel with proposed new chemical composition was prepared in laboratory conditions. The texture analysis has shown that suggested procedure led the formation of sufficiently strong $\{110\}<001>$ Goss texture during the short time period of a final annealing process, which is comparable to that obtained in the conventionally treated grain-oriented steels.

Keywords: Grain-oriented Fe-Si steels, abnormal grain growth, VC inhibitors, microstructure, texture
\end{abstract}

\section{Introduction}

Grain-oriented (GO) electrotechnical steels are soft magnetic materials widely used as the core materials in electrical transformers. It is the only product manufactured in the steel industry that applies the secondary recrystallization phenomenon, and its magnetic properties are closely related to the secondary recrystallization texture which allow us to minimize watt losses thanks to the presence of Goss grains with sharpness $\{110\}<001>$ crystallographic orientation $[1,2]$. The strong $\{110\}<001>$ texture has the easiest magnetization along the direction $<001>$, making the magnetic properties extremely anisotropic. This texture is formed during the complex abnormal grain growth (AGG) [3]. The small precipitates, also called inhibitors play a critical role in the abnormal grains nucleation. They inhibit the normal grain growth and thus support the development of sharp Goss texture during the secondary recrystallization annealing $[4,5]$.

Method of grain-oriented silicon steel production, invented by Norman P. Goss [6] in the 1930s, led to revolutionary reductions in core losses for 3\% silicon-iron largely through the development of texture or preferred orientation via the process of secondary recrystallization. Later, Takahashi and Harase $[7,8]$ categorized the three conventional methods for manufacturing GO silicon-steel on an industrial basis, i.e., the Nippon Steel method (called Orientcore HI-B), the Kawasaki method (called RG-H), and the Armco method for manufacturing of conventional GO silicon-steel. Although these technologies provide the
Goss texture in the grain-oriented steels with sufficiently high sharpness, the exact background of the aforementioned texture formation is still not clearly understood. It is well known that the Goss texture is formed via secondary recrystallization during the long time final box annealing. The steel is typically heated up to $1200^{\circ} \mathrm{C}$ with a very low heating rate of $15-25^{\circ} \mathrm{C} / \mathrm{h}$ and subsequently it is annealed at this temperature for around $30-40$ hours. The above mentioned process of annealing proceeds for 100-120 hours $[9,10]$. In nearly every stage until box annealing there are crucial factors for the inhibition system which has to restrain normal grain growth and to control secondary recrystallization. The maximal inhibition effect is obtained with a homogeneous distribution of particles having diameter in the range of $50-100 \mathrm{~nm}[11,12]$. On the other hand, it is necessary to provide the presence of $\{110\}<001>$ oriented grains in the primary recrystallized fine grained matrix $[13,14]$.

In our present work, we suggest a novel approach for the preparation of the $\mathrm{GO}$ steels that consist of application of $\mathrm{VC}$ nanoparticles as inhibitors in combination with strain-induced grain boundary motion mechanism and continuous annealing in dynamic conditions during the secondary recrystallization. This approach considerably reduces the preparation time as the whole process lasts only several minutes [15]. Special interest was focused on the study of the influence of VC particles on the grain growth and texture development. The abnormal grain growth thermal activation [16] is supported by the strain-induced grain boundary motion. This proposed procedure could lead to

* INSTITUTE OF MATERIALS RESEARCH OF SLOVAK ACADEMY OF SCIENCES, KOŠICE, SLOVAKIA

** TECHNICAL UNIVERSITY OF KOŠICE, FACULTY OF METALLURGY, INSTITUTE OF MATERIALS, KOŠICE, SLOVAKIA

\# Corresponding author: ipetryshynets@saske.sk 
a marked reduction of production costs of the grain-oriented electrical steels providing energy savings with favorable impact on environment.

\section{Material and experimental procedure}

The material investigated in this work was a laboratory prepared grain-oriented silicon steel with the following chemical composition, by wt. \%: $\mathrm{C}=0.0360, \mathrm{Mn}=0.0220, \mathrm{Si}=3.1500$, $\mathrm{P}=0.0030, \mathrm{Al}=0.0150, \mathrm{~N}=0.0011, \mathrm{~V}=0.0320$. The samples of this steel were marked SC. The schematic diagram of thermomechanical treatment of experimental slab is shown in Fig. 1.

It can be seen that the present method of GO steel preparation differs from the Nippon Steel method (HI-B) [7] by temper rolling process after decarburization annealing as well as by secondary recrystallization annealing in dynamic conditions. The strips of $2.2 \mathrm{~mm}$ thickness were taken after the four-stage final hot rolling process. Then these hot rolled samples were subjected to the coiling processes at $660^{\circ} \mathrm{C}$ and $580^{\circ} \mathrm{C}$ during 45 mins, see Fig. 1. After this operation, they were cold rolled to $0.35 \mathrm{~mm}$ of thickness with reduction of $\varepsilon \sim 84 \%$.

The next step was primary recrystallization annealing in the temperature range $850^{\circ} \mathrm{C}-1100^{\circ} \mathrm{C} / 10$ mins in an atmosphere of $100 \% \mathrm{H}_{2}$ and with subsequent decarburization annealing which was carried out in wet atmosphere of $\mathrm{H}_{2}(75 \%)+\mathrm{N}_{2}$ (25\%) mixed gas (dew point $\sim+40^{\circ} \mathrm{C}$ ) at $850^{\circ} \mathrm{C} / 10$ mins. After these processes, the experimental steel sheets were temper rolled within one pass at room temperature and annealed during the
5 min (secondary recrystallization) in pure hydrogen $\mathrm{H}_{2}$ atmosphere upon dynamical conditions. The thicknesses of temper rolled experimental samples are presented in Table 1. Prior to the secondary recrystallization, the investigated steel samples were prepared by electric spark cutting into small strips with dimensions of $3 \mathrm{~cm} \times 1 \mathrm{~cm}$ with the longest side parallel to the rolling direction.

TABLE 1

Thickness of experimental strips after temper rolling

\begin{tabular}{|c|c|c|c|}
\hline № & $\begin{array}{l}\text { Thickness of strips } \\
\text { after cold rolling } \\
(\mathrm{mm})\end{array}$ & $\begin{array}{l}\text { Temper rolling } \\
\text { reduction } \\
(\%)\end{array}$ & $\begin{array}{l}\text { Thickness of strips } \\
\text { after temper rolling } \\
\text { (mm) }\end{array}$ \\
\hline 1 & \multirow{4}{*}{0.350} & 2 & 0.343 \\
\hline 2 & & 4 & 0.336 \\
\hline 3 & & 6 & 0.329 \\
\hline 4 & & 8 & 0.322 \\
\hline
\end{tabular}

Carbon extraction replicas for examination of VC particles in the investigated materials were prepared from metallographic samples and then they were analyzed by means of JEOL JEM2100F high-resolution scanning transmission electron microscope (STEM) with field emission electron gun (FEG) operating at accelerating voltage of $200 \mathrm{kV}$ equipped with EDX detector for elemental analysis.

The most representative samples of investigated steel were chosen for the microstructure and texture analyses. The microstructure analysis of the specimens was carried out with “Olympus Inverted System Metallurgical Microscopy GX-71".

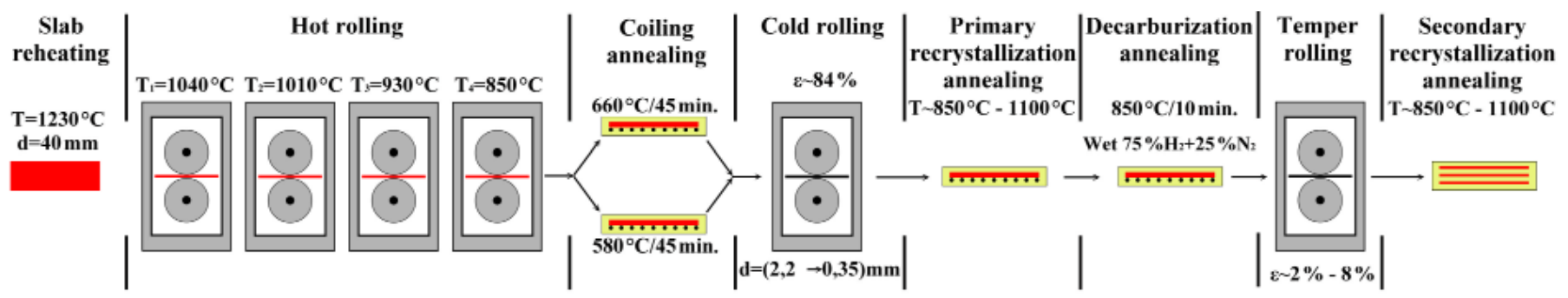

Fig. 1. Scheme of laboratory treatment of experimental steel
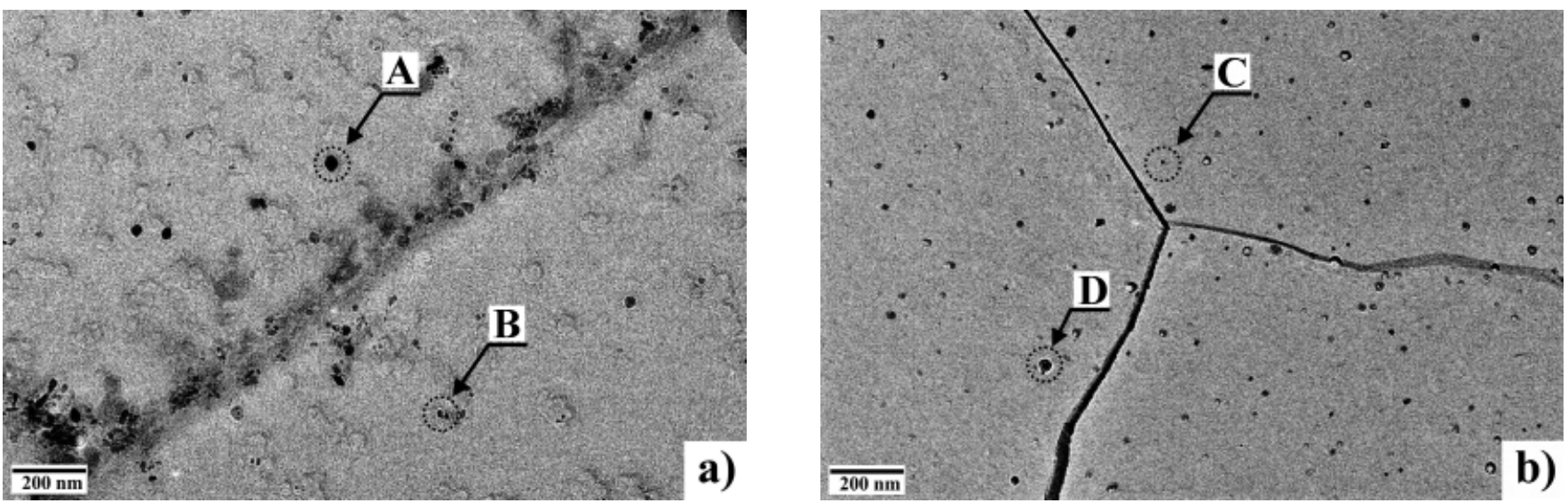

Fig. 2. Bright field TEM images of carbon extraction replicas showing the grain boundaries and distribution of secondary phase particles in SC1 (a) and SC2 (b) specimens 
JEOL JSM 7000F FEG scanning electron microscope with EBSD detector was used to perform the texture analysis. The crystallographic orientation of grains was carried out in the normal direction plane for each sample of $2 \mathrm{~cm} \times 1 \mathrm{~cm}$ in size.

\section{Results and discussions}

The chemical composition of experimental material was proposed to produce GO steel containing majority of vanadium carbides (VC) secondary phase particles. The formation of $\mathrm{VC}$ inhibitors and their influence on the start of the abnormal grain growth during the secondary recrystallization annealing was investigated at two coiling temperatures $660^{\circ} \mathrm{C}$ and $580^{\circ} \mathrm{C}$ during the $45 \mathrm{~min}$. Therefore, the laboratory prepared hot rolled steel sheets were divided into two groups of specimens and were marked as SC1 and SC2 strips. The Fig. 2a,b show the distribution of second phase particles on the carbon replicas prepared from the $\mathrm{SC} 1$ samples after the coiling at $660^{\circ} \mathrm{C}$ and $\mathrm{SC} 2-580^{\circ} \mathrm{C}$, respectively. As shown, the obtained second phase particles are very sensitive to the value of coiling temperature. In case of the $\mathrm{SC} 1$ specimens, the $\mathrm{VC}$ precipitates are mostly located close to the grain boundaries forming the clusters in the size ranging from 50 to $200 \mathrm{~nm}$. A different situation is observed in case of the $\mathrm{SC} 2$ specimen which was held at the lowest cooling temperature $580^{\circ} \mathrm{C}$ during $45 \mathrm{~min}$, see Fig. $2 \mathrm{~b}$. Here, the TEM image shows the area where three grain boundaries converge with a homogenous distribution of inhibitor particles, referring mostly to VC precipitates. The size of most of the precipitates is relatively fine with a typical diameter ranging from 10 to $40 \mathrm{~nm}$, allowing effective pinning effect on the grain boundaries. The representative high resolution TEM image of atomic planes of observed particle C (see Fig. 2b) and EDX spectra of some precipitates are presented in Fig. 3a,b respectively. As one can see the vanadium carbides of different size and distribution are the dominant precipitates in both investigated samples. These inhibi- tors are more populated in the vicinity of grain boundaries but also uniformly distributed on the whole bulk of detected grains. All EDX spectra of detected particles A, B, C and D showed the carbon and vanadium peaks, see Fig. 3b. The distance between the atomic plains of crystal lattice of one of observed particles was measured as $0.24 \mathrm{~nm}$ and corresponds to the $\{111\}$ planes of vanadium carbide crystal [17], that a higher intensity of the carbon peak in comparison with vanadium as well as copper peaks are detected in the EDX spectra due to the supporting carbon film and the copper mesh TEM grid, respectively. The carbon replica also contains oxygen and silicon as silicon oxide because of oxidation of the steel surface before carbon film deposition and during carbon replica extraction.

Based on these results it could be concluded that the experimental specimen $\mathrm{SC} 2$ is characterized by optimal distribution of $\mathrm{VC}$ particles and their size. The specimen $\mathrm{SC} 1$ which was held at $660^{\circ} \mathrm{C}$ exhibits a less favorable distribution of inhibitors and their size. Such distribution of particles significantly reduces the pinning effect on grain boundaries which is desirable for abnormal grain growth with Goss crystallographic texture during the secondary recrystallization annealing. One can conclude that the quantitative evolution of size and volume fractions of $\mathrm{VC}$ precipitations in materials $\mathrm{SC} 1$ and $\mathrm{SC} 2$ changes depending on the value of coiling temperature and holding time.

The microstructure of the cold rolled SC2 specimen after primary recrystallization at $850^{\circ} \mathrm{C}$ for $10 \mathrm{~min}$ and subsequent decarburization annealing is presented in Fig. 4. As shown the material is characterized by fine grained microstructure with relatively uniform distribution of grains with mostly ellipsoidal or rough boundaries. The average grain size of this sample was around $20 \mu \mathrm{m}$.

The primary recrystallized grain matrix of cold rolled SC2 specimen obtained after the annealing at higher temperatures than $850^{\circ} \mathrm{C}$ is presented in Fig. 5. The first type is primary recrystallized microstructure with the average grain size of about $35 \mu \mathrm{m}$ which was obtained after annealing at $1025^{\circ} \mathrm{C} / 10 \mathrm{~min}$, see
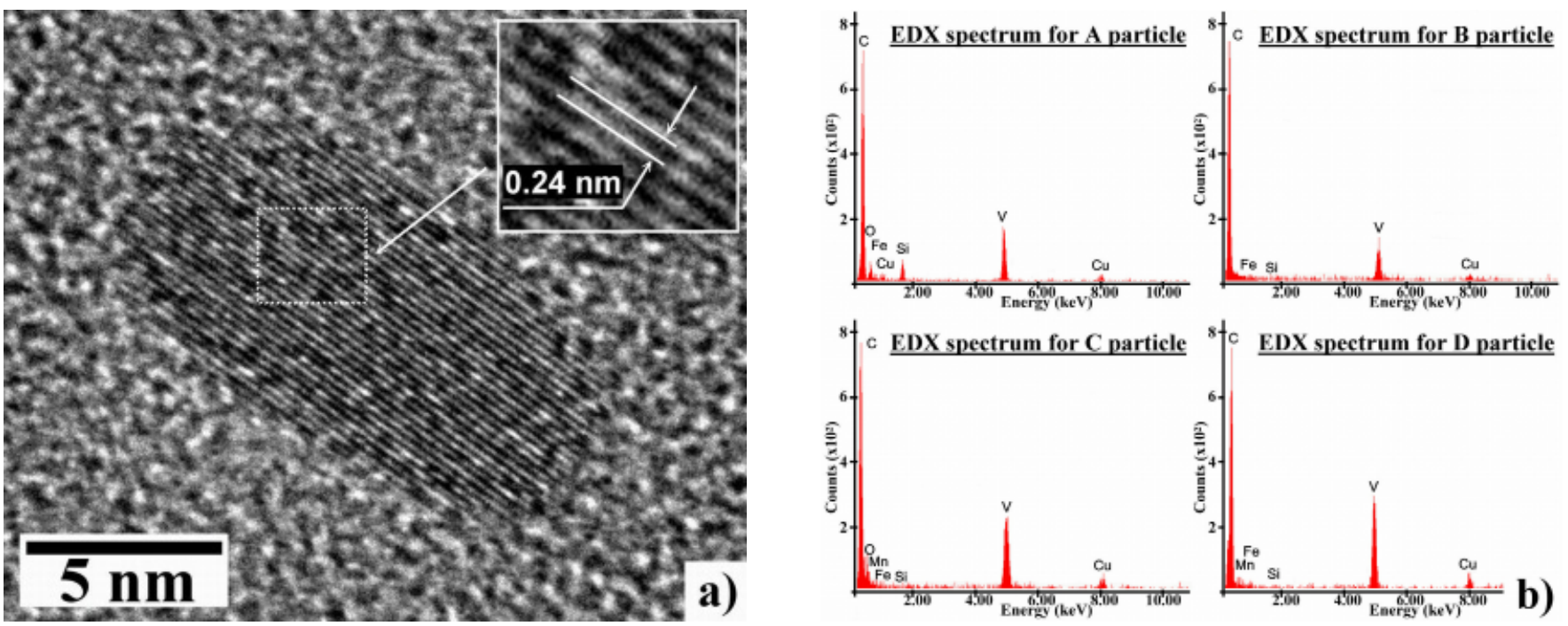

Fig. 3. The HRTEM micrograph and distance evaluation between the lattice of VC nano particle (a), EDX spectrum of some inhibitors (b) marked in Fig. 2 


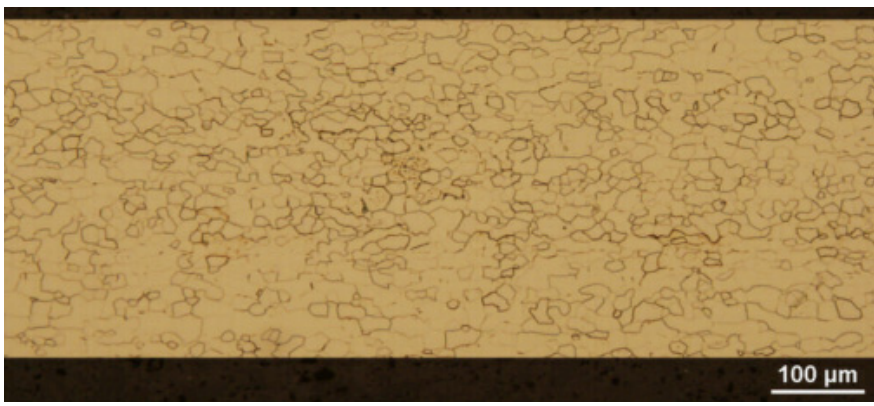

Fig. 4. The primary recrystallized microstructure of $\mathrm{SC} 2$ specimen after decarburization annealing at $850^{\circ} \mathrm{C} / 10 \mathrm{~min}$
Fig. 5a. Here the fine grain matrix that was pinned by inhibitors and redundant carbons in a form of spheroidal graphite which precipitate on the grain boundaries is distributed uniformly through the cross - section of specimen. It could be concluded that the annealing temperature of $1025^{\circ} \mathrm{C}$ is inefficient to start normal or abnormal grain growth.

The normal grain growth development with average grain size of $150 \mu \mathrm{m}$ was achieved by increasing the annealing temperature up to $1075^{\circ} \mathrm{C}$, see Fig. $5 \mathrm{~b}$. It can be seen that this homogenous polygonal microstructure is characterized by a uniform distribution of ferrite grains. The change of average grain size of cold
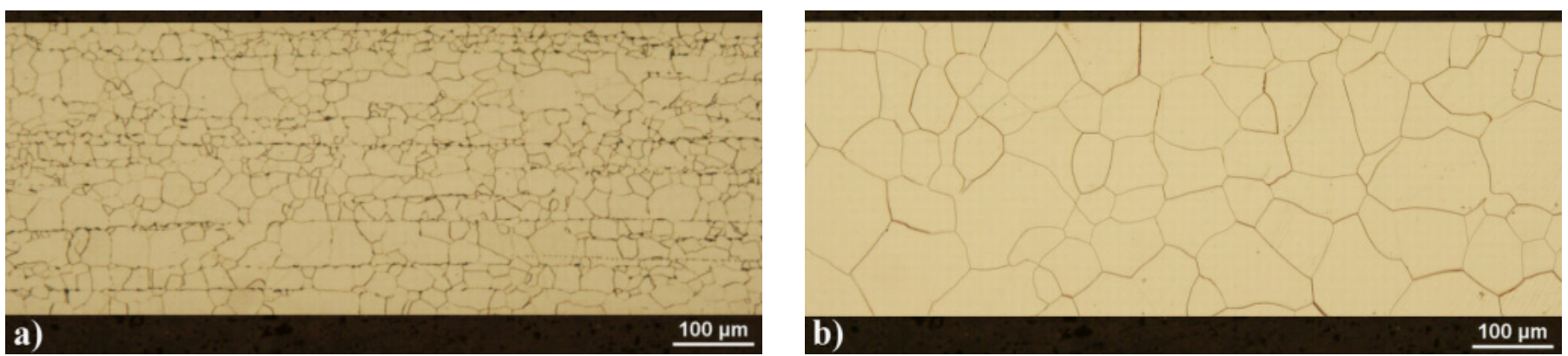

Fig. 5. The microstructure of SC2 steel treated after cold rolling and primary recrystallization annealing under the dynamical conditions for 10 min at $1025^{\circ} \mathrm{C}(\mathrm{a})$ and $1075^{\circ} \mathrm{C}(\mathrm{b})$

rolled SC2 samples during the primary recrystallization annealing in the range from $850^{\circ} \mathrm{C}$ to $1100^{\circ} \mathrm{C}$ is presented in Fig. 6. It is obvious that this dependence is divided into two parts. As one can see the value of average grain size in the range of $850^{\circ} \mathrm{C}-1050^{\circ} \mathrm{C}$ is changed by minor variations. The significant change of grain size in these samples is registered at the $1050^{\circ} \mathrm{C}$ due to start of the normal grain growth process with the outgoing microstructure presented in Fig. 5b. The further increase and plateau behavior of average grain curve should lead to the conclusion that the normal grain growth with polygonal structure is completed.

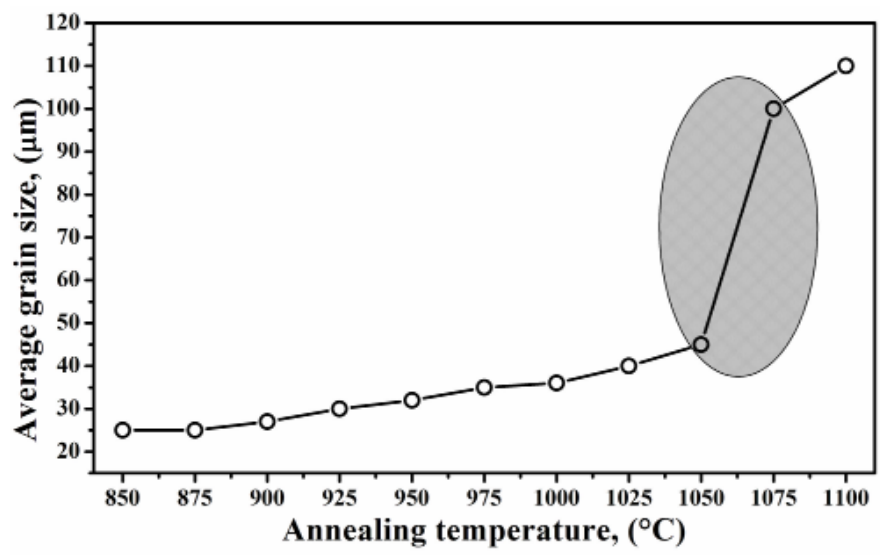

Fig. 6. Dependence of average grain size of cold rolled SC2 samples after primary recrystallization annealing during $10 \mathrm{~min}$

The secondary recrystallized microstructures of the SC2 samples after different thermo-mechanical processing are shown in Figs. 7,8. In order to achieve the optimal conditions for ab- normal grain growth with appropriate Goss crystallographic orientation the temper rolling process was performed on the strips which were taken after the primary recrystallization annealing with subsequent decarburization annealing. The secondary recrystallized microstructure of SC2 samples which were obtained after primary recrystallization at $850^{\circ} \mathrm{C} / 10 \mathrm{mins}$, decarburization, temper rolling with $4 \%$ of deformation with subsequent finally annealing at $1025^{\circ} \mathrm{C}$ and $1075^{\circ} \mathrm{C}$ during the $5 \mathrm{~min}$ in dry hydrogen atmosphere, is presented in Fig. 7a,b, respectively. As one can see the both microstructures presented in the Fig. 7 are characterized by inhomogeneous distribution of coarse grains with average size of about $500 \mu \mathrm{m}$. The distinguished type of secondary recrystallized microstructure of the same samples have been developed after primary recrystallization at $1075^{\circ} \mathrm{C}$ for 10 mins, decarburization annealing with subsequent application of temper rolling with $4 \%$ of deformation and final annealing at $1025^{\circ} \mathrm{C}$ and $1075^{\circ} \mathrm{C}$ for $5 \mathrm{~min}$ in dynamic conditions. These microstructures are presented in Fig. 8a,b, respectively. Here, the other approach of treatment of SC2 samples allows achieving the better microstructural parameters from the magnetic properties point of view. Fig. 8a presents the microstructure of the sample after the secondary recrystallization at $1025^{\circ} \mathrm{C}$ for $5 \mathrm{~min}$. Here, the abnormal grain growth is stopped by the grain matrix with strongly marked features of secondary recrystallization. Further increase of the annealing temperatures up to $1075^{\circ} \mathrm{C}$ leads to initiation of abnormal grain growth through the whole the cross-section of present steel sheet, see Fig. 8b. Here, this sample displays homogenous huge grains with average size of about one millimeter without other small parasitic grains or grains with secondary recrystallized matrix. 


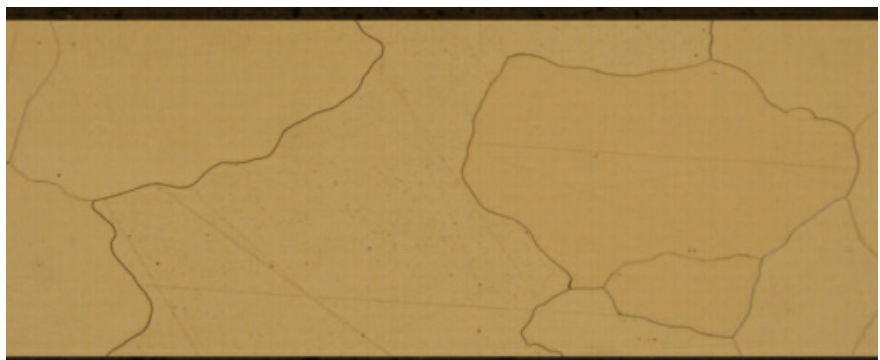

Fig. 7. The microstructure of SC2 steel obtained after the primary recrystallization at $850^{\circ} \mathrm{C} / 10 \mathrm{~min}$, decarburising annealing, temper rolling with $4 \%$ of deformation and subsequent secondary recrystallization for 5 minutes at $1025^{\circ} \mathrm{C}$ (a) and $1075^{\circ} \mathrm{C}(\mathrm{b})$
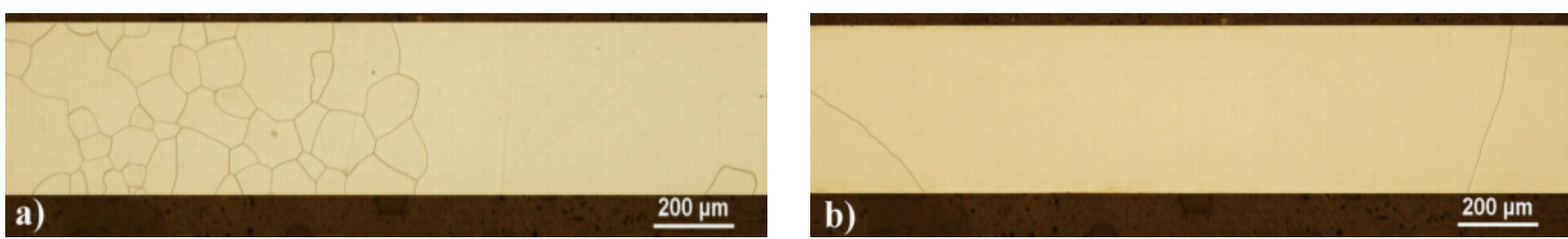

Fig. 8. The secondary recrystallized microstructure of SC2 steel after the primary recrystallization at $1075^{\circ} \mathrm{C}$ during 10 min, decarburising annealing, temper rolling with $4 \%$ of deformation and subsequent final annealing at dynamical conditions for 5 minutes at $1025^{\circ} \mathrm{C}$ (a) and $1075^{\circ} \mathrm{C}(\mathrm{b})$

Fig. 9 shows results obtained from the EBSD measurements which present intensities of particular crystallographic texture components. Here, EBSD analysis in the form of orientation distribution section (ODF) taken at $\varphi_{2}=45^{\circ}$ was carried out on the specimen SC2 presented in Fig. $5 \mathrm{~b}$ and $8 \mathrm{~b}$, see Fig. 9a,b, respectively. The common texture can be represented also by orientation fibers in the Euler space taken from ODF. The most relevant fibers for the investigated grain-oriented steel are $\gamma$-, $\alpha$-, and $\eta$-fiber which are presented in Fig. 10. As one can see, Fig. 9a shows that our laboratory cold rolled steel SC2 after the primary recrystallization at $1075^{\circ} \mathrm{C} / 10 \mathrm{~min}$ and decarburization (see Fig. 5b) is characterized by dominance of $\gamma$ - and $\alpha$-fibre in combination with deviation Goss texture (deviated from its ideal $\{110\}<001>$ orientation) which is enhanced in comparison with so called deformed texture component $\{111\}<110>$. The dominant Goss texture can be expressed the $\eta$-fiber which shows marked intensity of the near Goss texture components (i.e. deviated Goss orientation).

The $\gamma$ fiber represents the intensity of deformed texture component $\{111\}<110>$, see Fig. 10 . On the other hand the EBSD analysis shows very strong Goss texture component of huge grains which was achieved after the complete abnormal grain growth which was obtained after the secondary recrystallization at $1075^{\circ} \mathrm{C} / 5 \mathrm{~min}$, see Figs. $9 \mathrm{~b}$ and 10 . This fact suggests that abnormal grain growth with sharp Goss crystallographic orientation $\{110\}<001>$ is achieved on the specimens which were treated by our proposed thermo-mechanical method using the combination of temper rolling process with small reduction and subsequent final annealing in dynamic conditions. This method was applied to specimen with microstructural state presented in Fig. 5a. It means that series combination such as primary recrystallization annealing at $1075^{\circ} \mathrm{C} / 10 \mathrm{~min}$, decarburization
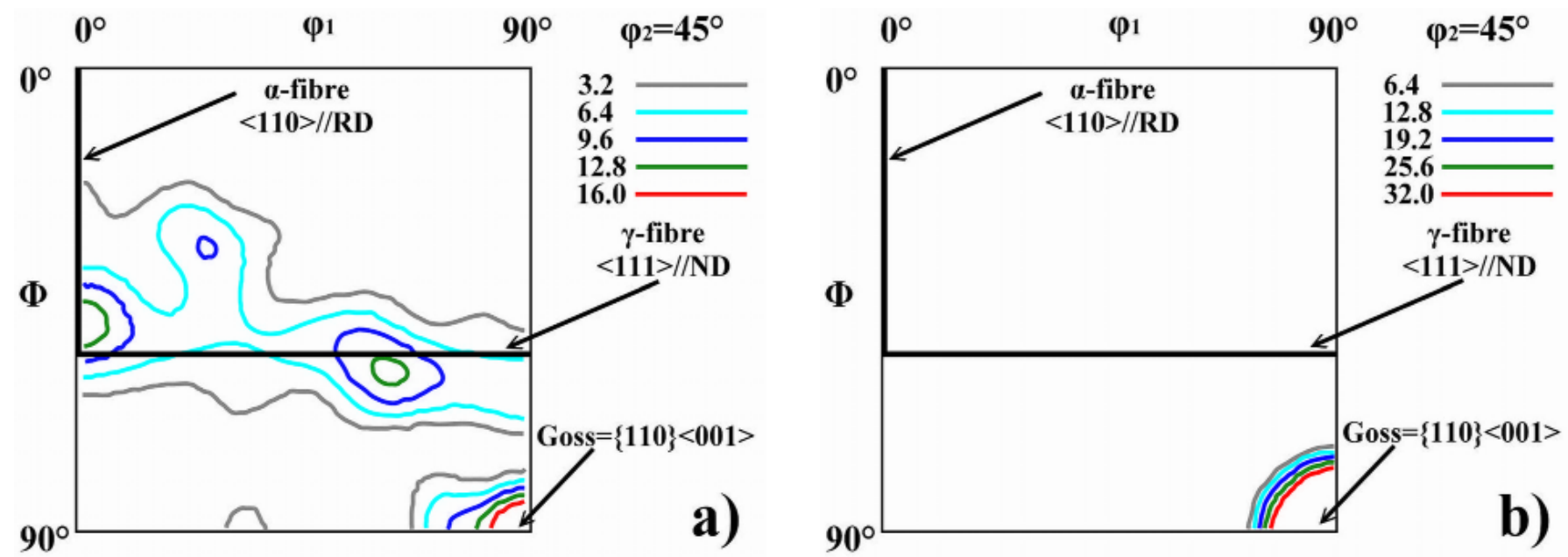

Fig. 9. ODF section taken at $\varphi_{2}=45^{\circ}$ description the crystallographic orientation of grains which are presented in Fig. $5 \mathrm{~b}$ (a) and in Fig. $8 \mathrm{~b}$ (b) 

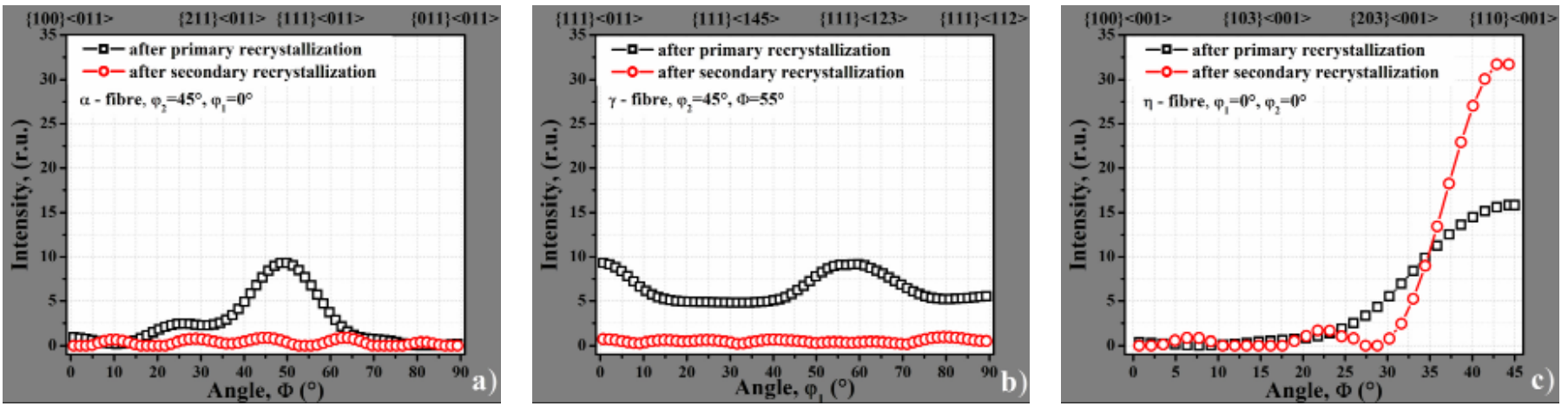

Fig. 10. The variation of orientation density along $\alpha$-fiber (a), $\gamma$-fiber (b) and $\eta$-fiber (c) in dependence of the applied model temperature annealing in the investigated grain-oriented steel

annealing at $850^{\circ} \mathrm{C} / 10 \mathrm{~min}$, temper rolled with $4 \%$ of deformation and secondary recrystallization annealing in dynamic conditions at $1075^{\circ} \mathrm{C} / 5 \mathrm{~min}$ allow us to achieve the appropriate coarse grained microstructure with sharp Goss crystallographic orientation which is desirable for this kind of steel from their magnetic properties point of view.

The observed abnormal grain growth of steel with $\mathrm{VC}$ nano particles led to elaboration of sufficiently sharp $\{110\}<001>$ Goss texture which is equal to that obtained in conventionally treated GO steels. This means that the proposed heat treatment and used VC precipitations at the appropriate coiling temperatures develops material of equal quality at significantly short-time of final annealing treatment in comparison to the conventional route of the GO steel production.

\section{Conclusions}

In summary we have shown that the observed strain induced abnormal grain growth under the dynamic heat treatment conditions in steel with the inhibitor system on the basis of VC nano - particles achieved sufficiently sharp $\{110\}<001>$ Goss texture which is similar to that obtained in conventionally treated GO steels. There are two distinguished secondary recrystallization phenomena observed. First one was the abnormal grain growth of the Goss grains that was detected at relatively low temperatures $1025^{\circ} \mathrm{C}-1075^{\circ} \mathrm{C}$ under influence of unconventional dynamical heat treatment condition and deformation gradient through the thickness of steel sheet. The second one is the abnormal grain growth with very strong Goss texture component inhibited by $\mathrm{VC}$ second phase particles in the range of $10-40 \mathrm{~nm}$ which were precipitated near the grain boundaries at low coiling temperature $580^{\circ} \mathrm{C}$. This means that the proposed novel approach markedly reduces production costs of the grain-oriented electrical steels providing potential energy savings with favorable impact on the environment.

\section{Acknowledgements}

This work was partially supported by the Slovak Grant Agency VEGA, project No. 2/0081/16 and No. 2/0120/15. Also, the work was realized within the frame of the project ITMS 26220220037, ITMS 26220220061 and ITMS 26220220064

\section{REFERENCES}

[1] Martin F. Littman, J. Magn. Magn. Mater. 26, 1-10 (1981).

[2] W. Guo, W. Mao, J. Mater. Sci. Technol. 26, 759-762 (2010).

[3] K. Gunther, G. Abbruzzese, S. Fortunati, G. Ligi, Proceedings of SMM16, Düsseldorf: Germany, 41-51 (2003).

[4] N. Bernier, C. Xhoffer, T. Van De Putte, M. Galceran, S. Godet, Materials Characterization 86, 116-126 (2013).

[5] D. Dorner, S. Zaefferer, L. Lahn, D. Rabbe, J. Magn. Magn. Mater. 304, 183-186 (2006).

[6] N.P. Goss USA. 1, 965, 559 (1934).

[7] N. Takahashi, Y. Suga, H. Kobayashi, J. Magn. Magn. Mater. 160, 98-101 (1996).

[8] N. Takahashi, J. Harase, Mater. Sci. Forum 204-206, 143-154 (1996).

[9] T. Kubuta, M. Fujikura, Y. Ushigami, J. Magn. Magn. Mater. 215-216, 69-73 (2000).

[10] M. Morawiec, Scripta Materialia 64, 466-469 (2011).

[11]Y. Li, W. Mao, P. Yang, J. Mater. Sci. Technol. 27, 1120-1124 (2011).

[12] C. Gheorghies, A. Doniga, Journal of Iron and Steel Research International 16, 78-83 (2009).

[13] A.L. Etter, T. Baudin, R. Penelle, Scripta Materialia 47, 725-730 (2002).

[14] Y. Wang, Y. Xu, Y. Zhang, S. Xie, Y. Yu, G. Wang, Materials Research Bulletin 69, 138-141 (2015).

[15] V. Stoyka, F. Kovac, O. Stupakov, I. Petryshynets, Materials Characterization 61, 1066-1073 (2010).

[16] F. Kovac, V. Stoyka, I. Petryshynets, J. Magn. Magn. Mater. 320, e627-e630 (2008).

[17] T. Epicier, D. Acevedo, M. Perez, J. Philosophical Magazine 88, 31-45 (2008). 